\title{
Application of the Ride Protocol in a Case of Childhood OCD : A Case Study
}

\author{
Srishti Saha
}

Consultant Clinical Psycholocl, Fortis Hospital

\begin{abstract}
Cognitive Behavioural Therapy (CBT) as a treatment of choice for adults with Obsessive Compulsive Disorder (OCD) is well substantiated by literature. For children, however, the use of CBT might pose a number of problems arising from their lack of maturity, cognitive sophistication, and dexterity with language. The RIDE protocol of Wagner ${ }^{1}$ is considered to be a developmentally appropriate adaptation of CBT that can be used in the management of OCD in children. The present case study explored the application of this protocol in the management of an 8 year old boy's OCD symptoms. With therapy, the child was able to reduce his distress in response to the worrying thoughts and was successful in refraining from his compulsive acts. However, the case also highlighted that with childhood OCD, parental support and the involvement of family members in therapy is of critical importance for successful long term outcomes.
\end{abstract}

\section{INTRODUCTION}

Obsessive-Compulsive Disorder is characterised by a pattern of repetitive unwanted thoughts, images and impulses (obsessions) in response to which the person feels compelled to perform certain repetitive ritualistic acts or behaviours (compulsions). Estimated prevalence rates for OCD among children and adolescents range between $0.25 \%-4 \%$. $\%^{2,3,4}$. For adults, CBT represents the treatment of choice for non-pharmacological techniques. For children, however, certain factors might make the application of CBT difficult, such as a lack of maturity, cognitive mindedness and language mastery. Owing to these factors, an adaptation of CBT, suitable for use with children, is needed. The RIDE protocol of Wagner is considered to be a developmentally appropriate adaptation of CBT that can be used in the management of OCD in children.

\section{CASE DESCRIPTION : PRESENTATION}

An 8 year old boy presented with the complaints of anxiety centered on the themes of dirt, contamination and the idea of sin. He expressed marked anxiety regarding fear of contamination by urine. To neutralize this anxiety, he would engage in repeated washing of hands after passing urine to ensure they were clean. He almost had a constant sense of fear that drops of urine were being released in his undergarments, making then unclean as a result of which he felt dirty almost all the time and was compelled to wash his hands numerous times throughout the day. During clinical interview, the child reported experiencing such thoughts repeatedly in spite of his strongest wish not to have such thoughts He told the clinician that he feared that if he did not engage in the washing behaviours, it would be equivalent to sinning and God would then punish him. According to him, as part of this punishment, some harm was likely to befall him (e.g., his birthday would not go well or his parents would be taken away from him, or that they would become poor). The last fear of becoming poor was so strong that he would urge his father not to buy anything new or spend too much money. 
Alongside these thoughts, the child was found to become overly preoccupied with and hyper-vigilant to the possibility of his sinning. He feared that if his feet touched something or someone, he was actually committing a sin deserving of punishment. He worried that if he was rude to someone, then that might be considered a sin too. As a response to such thoughts, he would compulsively seek reassurance from his family members that he was in fact not committing a sin and that God would not punish him. They would usually respond by saying that God does not punish little children. Owing to such thoughts, the child was being unable to focus on his studies or enjoy other leisure activities. The parents reported that he appeared quieter and gloomier and developed a listless, fatigued appearance. His interaction with peers decreased too.

\section{RELEVANT FAMILY HISTORY}

Both the parents of the child had a history of psychiatric illness. His father had significant features of Panic Disorder and Generalized Anxiety Disorder. The mother had features of severe depression with a history of attempted suicide. There was also significant friction between the parents and the home atmosphere was uncongenial and disturbed. The parents often quarreled and argued in front of the child, and were even physically aggressive towards each other. These confrontations were so intense that neighbours, and on one occasion even the police, had to intervene (No legal case was filed, however). There was also significant disharmony between the child's mother and his paternal grandmother. They often had disagreements about day to day matters of the house and these led to very heated verbal arguments. The child felt highly distressed during such incidents, particularly with confrontations between his parents. During such incidents, he reported feeling alone and helpless and did not have anybody to talk to or share his fears with. He felt particularly scared that his parents might get seriously injured or that the police might arrest them. He also worried that his mother might attempt suicide again, as she had done in the past.
Another important aspect evident in case history was that the child's grandmother frequently used the threat of God's punishment as a way of disciplining the child and controlling his mischievous behaviours.

\section{RELEVANT SOCIAL HISTORY}

The family did not maintain ties with relatives; participation in social activities was reported to be minimal too. The child felt unable to form close bonds with friends due to his home environment. He felt that if his friends wanted to come home, he would be embarrassed to invite them due to the hostile atmosphere at home.

\section{PSYCHOPATHOLOGY \\ FORMULATION}

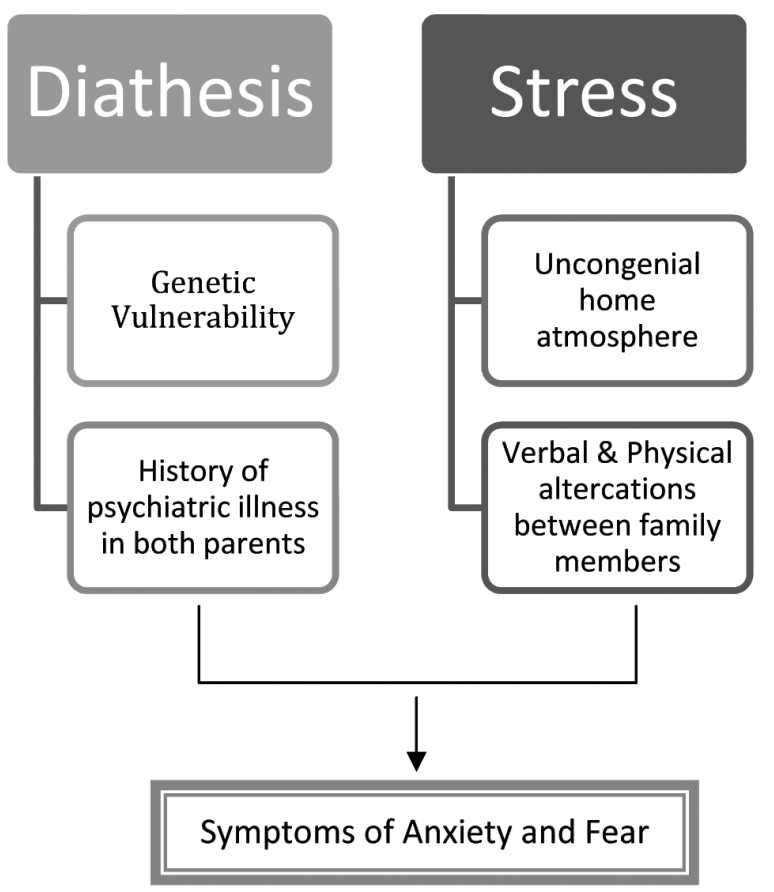

Interactive model of diathesis-stress reaction (Adapted from Monroe \& Simons, 19915)

\section{THERAPY PROCESS}

Following the RIDE protocol, therapy was initiated with psycho-education about the illness, in a language that the child would be able to follow 
easily. The metaphor of worry being a hill and overcoming his anxiety being equivalent to riding a bicycle up that hill was used. He was explained that stopping compulsive acts is akin to the difficulty of riding up-hill, but that if he wanted to reach the top, he would have to persist, and that if he managed to do that, he could just coast for the rest of the downhill ride.

The four steps of the RIDE protocol were introduced to the child in subsequent sessions and are summarized below.

R : Rename the Thought : Term such as "Worry Monster" was introduced to distance and externalize OCD thoughts, thereby reducing distress.

\section{I : Insist That YOU Are in Charge : Active assertion} was encouraged.

D : Defy OCD : Response prevention was emphasized by instructing and training the child to do the opposite of what his OCD thoughts tell him to do.

E : Enjoy Your Success : Strategies to provide positive feedback and reinforcement of success through positive self-statements and small rewards were introduced.

\section{THERAPY OUTCOME SO FAR}

With the help of this technique, in a span of 8 sessions, the child was able to control his worries to a significant extent. Even though, he reported worrying thoughts coming to him from time to time, he was not as distressed by them. He found it relatively easy to distract himself from the thoughts and refrain from feeding the monster" by engaging in the compulsions.

\section{OUTCOME MEASURES}

His CY-BOCS score went from 20 (moderate) in the first session to 8 (mild) at the $7^{\text {th }}$ session.

\section{FUTURE PLAN OF THERAPY}

Practice is required with the steps of treatment being followed for complete mastery over them. Relapse prevention needs to be focused upon after the remission of active symptoms whereby the child will need to be alerted to the fact that "slips" or relapses might happen, particularly at times of stress. He and the family members will require training in recognizing the early signs of relapse and immediate help-seeking behaviours will need to be emphasized.

\section{REFLECTIONS FROM THERAPY}

The family dynamics and inadequate support of parents is a critical problem with this case. Addressing family discord is of crucial importance as it is a constant source of stress for the child. Parents' follow up of their psychiatric illness will also need monitoring as it impacts their parenting strategies. Changing the grandmother's disciplining techniques and her cooperation with the same might also prove to be a difficult hurdle.

\section{CONCLUSION}

The case study made a detailed exploration of phenomenology of OCD in children. It provided an appreciation of the problems faced in following traditional CBT methods with children and the need for a CBT protocol specially adapted for use in children. It also allowed for the consideration of the unique contribution of the socio-cultural milieu in the development and maintenance of symptoms (such as the use of threats involving God's punishment as a disciplining technique) and highlighted the significance of involvement of family members in therapy for long-term successful outcomes. Although the findings show promise, as with all case studies, there is a difficulty in generalizing these findings and commenting on the feasibility and effectiveness of this protocol without its use in other cases. 
Ride Protocol in a Case of Childhood OCD

\section{REFERENCES}

1. Wagner AP. Cognitive-behavioral therapy for children and adolescents with obsessive compulsive disorder. Brief Treatment and Crisis Intervention 2003; 3(2) : 291-306.

2. Flament MF, Whitaker A, Rapoport JL, et al. Obsessive compulsive disorder in adolescence: an epidemiological study. J Am Acad Child Adolesc Psychiatry 1988; 27 : 764-71.

3. Heyman I, Fombonne E, Simmons H, et al. Prevalence of obsessive-compulsive disorder in the British nationwide survey of child mental health. Br J Psychiatry 2001; 179 : 324-9.

4. Douglass HM, Moffitt TE, Dar R, et al. Obsessive-compulsive disorder in a birth cohort of 18-year-olds : prevalence and predictors. J Am Acad Child Adolesc Psychiatry 1995; 34 : -31 .

5. Monroe SM, Simons, AD. Diathesis-stress theories in the context of life-stress research: Implications for the depressive disorders. Psychological Bulletin 1993; 110 : 406-425. 